\title{
Coordination of a three-level supply chain under disruption using profit sharing and return policy contracts
}

\author{
Ebrahim Manzari Tavakoli* and Mehdi Mirzaee
}

Department of Industrial Engineering, Iran University of Science \& Technology, Tehran, Iran

\section{H R O N I C L E}

\begin{tabular}{l}
\hline Article history: \\
Received June 2013 \\
Received in revised format \\
August $15 \quad 2013$ \\
Accepted August 302013 \\
Available online \\
September 42013 \\
\hline Keywords: \\
Three-level Supply chain \\
Coordination \\
Disruption \\
Profit sharing \\
Return policy \\
\hline
\end{tabular}

\section{A B S T R A C T}

\begin{abstract}
This paper studies a three-level supply chain with one retailer, one distributer and one manufacturer under disruption. First, we show that profit sharing and return policy contracts established between members can coordinate this supply chain. Then, we investigate the effect of demand disruption in supply chain and we illustrate the possibility of breaking the initial desirable coordination. We consider two possible scenarios for the demand disruption separately; afterwards we define the revised coordinator parameters to respond to their effect in supply chain. Numerical examples for validation and evaluation of our model are also elaborated.
\end{abstract}

(C) 2013 Growing Science Ltd. All rights reserved

\section{Introduction}

Coordination between independent firms in a supply chain relationship has been an important research issue, recently. Without coordination, distribution channel members determine their own decision variables independently in order to maximize one's own profits. It is well documented in marketing and economics literature that non-coordinated decisions lead to "double marginalization". It can decrease the competition of supply chain in comparison with other supply chains. Most of the researches focus on coordination schemes on supply chain by contractual approach. Cachon (2003) illustrated extensive researches on supply chain coordination with contracts approach. Tsay et al. (1998) provided a comprehensive review of supply chain contracts models. Mirzaee et al. (2012) illustrated the coordination of supply chain with combined contracts. A revenue sharing contract as a coordination mechanism has played an important role in coordination literature. Cachon and Larivier (2005) studied strengths and limitations of the revenue sharing contract in supply chain with one manufacturer and

* Corresponding author.

E-mail: Eb.tavakoli@gmail.com (E. Manzari Tavakoli)

(C) 2014 Growing Science Ltd. All rights reserved. doi: $10.5267 / j$. .jiec.2013.09.001 
multiple retailers. Dana and Spier (2001) considered the use of revenue sharing contract in a decentralized channel with a perfect competitive downstream market and stochastic demand. They explained that a revenue sharing contract could encourage downstream firms to choose the optimal values of supply chain. Krishnan and Winter (2011) evaluated the role of revenue sharing contract on supply chain. A return policy or in some articles buy back contract as a coordination mechanism tries to decrease the risk of ordering quantity for the retailer and will cause an increase in profit of supply chain. Some articles have used this contract in supply chain. Chen (2011) evaluated the effect of this contract and quantity discount contract in newsvendor model. Yao et al. (2008) analyzed the impact of changing of price in coordinating supply chain under return policy. They considered a model with one manufacturer and one retailer and showed that this contract would improve supply chain performance. Ding and Chen (2008) considered a coordination of a three-level supply chain with flexible return policy. This paper used a return policy and profit sharing contracts to coordinate a three-level supply chain without disruption firstly.

After an optimal coordination scheme has been established, the environment is often disrupted by some unexpected haphazard events, such as: terrorism, earthquake, financial crisis, raw material shortage, and so on. Disruption can significantly affect the performance of the supply chain members and planned coordination schemes. Therefore, it is meaningful to know how the supply chain can still be coordinated under different levels of disruptions. Disruption has evaluated in some of articles. Disruption could be happened in two kinds: disruption in supply or demand. Khedlekar (2012) and Azarmehr et al. (2012) considered a supply chain under supply disruption. Xiao et al. (2007) investigated the coordination mechanism for a two-level supply chain with retail competition when the demands are disrupted. Xiao and Qi (2008) assessed a coordination of two-level supply chain with two competing retailers. They considered an all-unit quantity discount and an incremental quantity discount in it. Qi et al. (2004), Chen and Xiao (2009), Huang et al. (2012) and Lei et al. (2012) also considered a two-level supply chain with demand disruption in different situations. Cao et al. (2013) considered the demand and cost disruptions in supply chain simultaneously. They also evaluated effect of disruption on revenue sharing contract and the optimal strategies with disruption.

Three-level supply chain coordination has been considered rarely because of complexity. Arshinder et al. (2009) introduced a theoretic model for coordination of three-level supply chains by using contracts. Munson and Rosenblatt (2001) considered a coordinating of three-level supply chain by quantity discount contract. Giannoccaro and Pontrandolfo (2004) showed a three-level supply chain could be coordinated by revenue sharing contracts, but they did not consider the effect of disruption in supply chain that would cause the coordination mechanism to be ruined. Some of the other articles such as Seifert et al. (2012) and Ding and Chen (2008) have considered coordination of three-level supply chains with different situations and disparate contracts. Neither of them considers the effect of disruption on coordination of supply chain.

This paper considers a three-level supply chain with one manufacturer, one distributer and one retailer. First, we define necessary conditions that the supply chain could be coordinated without disruption using a return policy contract between the manufacturer and the distributer, and also a profit sharing contract between the distributer and the retailer. A profit sharing contract has the same structure like revenue sharing contract, but only the profit of sales will share. Then we will evaluate the effect of demand disruption on our model and how it can affect the optimal parameters. The revised parameters for coordination under disruption will be defined. Disruption is considered in two scenarios: when the market demand increase and when the market demand decrease. Assumptions and parameters of model will be defined in part 2. Supply chain coordination without demand disruption in part 3 is considered. In part 4, we investigated on demand disruption in supply chain and all situations that can be happened and the coordination that may be broken off. Simulations and numerical examples for validation of our model are evaluated in part 5. At last, Conclusion is provided in part 6. 


\section{Assumptions and Notations}

We consider a three-level supply chain consisting of one retailer, one distributer and one manufacturer when one kind of product in supply chain would be produced. First, the retailer determines the order quantity to the distributer based on the prediction of stochastic demand and wholesale price that the distributer determines, afterwards the distributer and the manufacturer set their plans based on the order quantity. The manufacturer produces goods and then the products will be delivered to distributer and after that to the retailer before the beginning of the selling season. For establishing the model, the following notations are utilized:

$\mathrm{c}_{\mathrm{r}}$ : The retailer's marginal cost per unit,

$\mathrm{c}_{\mathrm{d}}$ : The distributer's marginal cost per unit,

$\mathrm{c}_{\mathrm{m}}$ : The manufacturer's marginal cost per unit,

q: The order quantity that the retailer request,

$\mathrm{p}$ : The retailer's price,

$v$ : The return price per unit of leftover inventories at the end of selling season that the distributer pays the retailer,

D: The demand during the selling season,

$\mathrm{w}_{\mathrm{dr}}$ : The wholesale price that is determined by distributer for the retailer per unit,

$\mathrm{W}_{\mathrm{md}}$ : The wholesale price that is determined by manufacturer for the distributer per unit,

$\mathrm{g}_{\mathrm{r}}$ : The shortage cost of retailer for not satisfied demand,

$\mathrm{g}_{\mathrm{d}}$ : The shortage cost of distributer for not satisfied demand,

$\mathrm{g}_{\mathrm{m}}$ : The shortage cost of manufacturer for not satisfied demand,

$\Pi_{r}$ : The expected profit function of the retailer,

$\Pi_{d}$ : The expected profit function of the distributer,

$\Pi_{m}$ : The expected profit function of the manufacturer,

П: The expected profit function of the total supply chain.

Also let $g=g_{r}+g_{d}+g_{m}, c=c_{r}+c_{d}+c_{m}$ and let $f$ be the probability density function and $F$ be the distribution function of the demand. We assume $F$ is differentiable and strictly non-decreasing and $F(0)=0 . \mu$ is an expected value of demand, $S(q)=q-\int_{0}^{q} F(y) d y$ is the expected sale, $I(q)=$ $(q-\mathrm{D})^{+}=q-S(q)$ is the expected surplus inventory and $L(q)=(\mathrm{D}-q)^{+}=\mu-S(q)$ is the expected lost sale where $(x)^{+}=\max \{0, x\}$. In basic model, we assume $w_{m d}>c_{m}, w_{d r}>c_{d}+w_{m d}$ and $\mathrm{v}<$ $\mathrm{w}_{\mathrm{dr}}$. Other needful parameters will be introduced during this paper.

\section{Supply chain without Disruption}

In this section, a three-level supply chain without disruption will be considered. First, for the coordination of supply chain, we need to earn the optimal parameters of centralized supply chain and after that, we can use them for establishing the coordination between members in decentralized model.

\subsection{Centralized supply chain}

In centralized supply chain, it is supposed that all members are trying to integrate the channel and to increase the total profit of the supply chain. Thus the objective function of the centralized supply chain to maximize the total profit of the supply chain which consists of the summation of all the manufacturer, the distributer and the retailer expected profits that can be calculated as follows:

$\Pi=\Pi_{r}+\Pi_{d}+\Pi_{m}$

That it equals to:

$\Pi=p s(q)-c q-g L(q)=(p+g) s(q)-c q-g \mu$ 
The following first order condition is necessary and not sufficient for coordination

$\frac{\partial \Pi}{\partial \mathrm{q}}=(p+g)(1-F(q))-c=0$.

Let $\mathrm{q}^{*}$ be an order quantity obtained from Eq. (3). So we would have

$F\left(q^{*}\right)=\frac{(p-c+g)}{(p+g)}$

Because $\frac{\partial^{2} \Pi}{\partial \mathrm{q}^{2}}=-(p+g) f(\mathrm{q})<0$, the expected profit function of total supply chain is concave. So the optimal order quantity of supply chain is equal to $q^{*}$ and the coordination of supply chain will be achieved when the retailer selects $q^{*}$. Therefore, we need to introduce a mechanism to encourage the retailer for selecting the optimal quantity of total supply chain.

\subsection{Decentralized supply chain without coordination}

In a decentralized supply chain in non-coordinated state, all the manufacturer, the distributer and the retailer decide separately to improve their profit share. First of all, the manufacturer determines its wholesale price for the distributer and the distributer determines its wholesale price for the retailer next. Finally, the retailer determines the order quantity based on the distributer's wholesale price. Consequently, the profits of members are as below:

For the retailer:

$\Pi_{r}=p s(q)-\left(w_{d r}+c_{r}\right) q+v I(q)-g_{r} L(q)$

For the distributer:

$\Pi_{d}=\left(w_{d r}-w_{m d}\right) q-c_{d} q-g_{d} L(q)-v I(q)$

For the manufacturer:

$\Pi_{m}=\left(w_{m d}-c_{m}\right) q-g_{m} L(q)$

So the retailer makes a decision to maximize its own profit, which means $\frac{\partial \Pi_{r}}{\partial q}=0$, therefore the retailer will determine $q_{r}^{*}$ as follows,

$F\left(q_{r}^{*}\right)=\frac{\left(p-w_{d r}-c_{r}+g_{r}\right)}{\left(p-v+g_{r}\right)}$

In order to $w_{d r} \geq c_{r}+c_{d}+c_{m}=c$ and because $F$ is non-decreasing and also based on Eq. (4) and Eq. (8), It is obvious that we would have $q_{r}^{*}<q^{*}$. Therefore, the coordination of supply chain will not be achieved. As a result, we need to use an appropriate contract or contracts for establishing supply chain coordination that is used in next part.

\subsection{Decentralized supply chain with coordination}

In this section, for establishing supply chain coordination, a profit sharing contract between the retailer and distributer and also a return policy between the distributer and manufacturer are introduced. Under the profit sharing contract between the distributer and the retailer, the retailer pays the distributer the wholesale price $w_{d r}$ for each unit purchased, plus a percentage of the sale profit that the retailer generates $\varphi_{d r}\left(0 \leq \varphi_{d r} \leq 1\right)$. $w_{d r}$ and $\varphi_{d r}$ are the parameters of this contract, which depend on each other; this means that it is necessary to define one of them and the other would be calculated from the equations. We use a return policy contract between the distributer and the manufacturer, the distributer pays the manufacturer the wholesale price for each unit purchased $w_{m d}$ but the manufacturer pays the distributer $\mathrm{b}\left(v<b<w_{m d}\right)$ as a return price per unit of leftover inventories at the end of selling 
season, therefore $w_{m d}$ and $\mathrm{b}$ are the parameters of this contract that dependent on each other. We need to define one of them and the other would be calculated from the equations. The leftover inventories have been given from the retailer to the distributer and instead, the distributer pays $v$ for them where it is permanent amount and defined before the selling season and this leftover inventories will be given to the manufacturer with return price of $b$, which is defined based on the contract and it can be changed in order to $w_{m d}$. According to the coordinator contracts, we can calculate the expected profit for each member as below:

$$
\left\{\begin{array}{l}
\Pi_{r}=\varphi_{d r} p s(q)-\left(w_{d r}+c_{r}\right) q-g_{r} L(q)+v I(q) \\
\Pi_{d}=\left(1-\varphi_{d r}\right) p s(q)+\left(w_{d r}-w_{m d}\right) q-c_{d} q+(b-v) I(q)-g_{d} L(q) \\
\Pi_{m}=\left(w_{m d}-c_{m}\right) q-b I(q)-g_{m} L(q)
\end{array}\right.
$$

We assume the parameters $\varphi_{d r}, b$ are given, we have two variables that they must be calculated, then for coordinating of the supply chain we will let the optimal order quantity of the centralized supply chain $q^{*}$ in Eq. (12) and Eq. (14).

Based on the expected profit function of the retailer, $\frac{\partial \Pi_{r}}{\partial \mathrm{q}}$ must be zero, so we would have:

$$
(1-\mathrm{F}(q)) \varphi_{d r} p-w_{d r}-c_{r}+g_{r}+v \mathrm{~F}(q)=0
$$

By rewriting of above equation and substituting of $q^{*}$, we can calculate $w_{d r}$ from below that we will call that as $w_{d r}{ }^{*}$.

$$
w_{d r}=\left(1-\mathrm{F}\left(q^{*}\right)\right)\left(g_{r}+\varphi_{d r} p\right)+v \mathrm{~F}\left(q^{*}\right)-c_{r}
$$

Based on the expected profit function of the distributer, $\frac{\partial \Pi_{d}}{\partial \mathrm{q}}$ must be zero, so we would have

$$
(1-\mathrm{F}(q))\left(\left(1-\varphi_{d r}\right) p+g_{d}\right)+w_{d r}-w_{m d}-c_{d}+(b-v) \mathrm{F}(q)=0
$$

By rewriting of above equation and substituting of $\mathrm{q}^{*}$, we can calculate $w_{m d}$ from below that we will name that as $w_{m d}{ }^{*}$.

$w_{m d}=\left(1-\mathrm{F}\left(q^{*}\right)\right)\left(\left(1-\varphi_{d r}\right) p+g_{d}\right)+w_{d r}-c_{d}+(b-v) \mathrm{F}\left(q^{*}\right)$

We do not have to consider the expected profit function of the manufacturer because the parameters $w_{d r}{ }^{*}, w_{m d}{ }^{*}$ will be calculated from Eq. (13) and Eq. (15). If the distributer and the manufacturer select $w_{d r}{ }^{*}, w_{m d}{ }^{*}$, respectively, the retailer will select the optimal quantity of supply chain, that means the coordination of supply chain will be achieved.

\section{Supply chain under Disruption}

In the above model, the static case of supply chain coordination was studied, but many factors will affect the demand, practically. When a disruption occurs, the coordination scheme of supply chain may become invalid and the coordination mechanisms can be ruined. Therefore, we consider the effect of demand disruption on supply chain coordination and also will introduce revised plans to the coordination. Disruption makes the market demand change from $f$ to $h$ and also the cumulative distribution function and the expected value will be $H$ and $\mu_{h}$, respectively, we have $S_{h}(q)=q-$ $\int_{0}^{q} H(y) d y$ as an expected sale, $I_{h}(q)=(q-\mathrm{D})^{+}=q-S_{h}(q)$ as an expected surplus inventory and $L_{h}(q)=(\mathrm{D}-q)^{+}=\mu_{h}-S_{h}(q)$ as an expected lost sale. After disruption, the new quantity of supply chain is not the optimal quantity $q^{*}$ that will cause the extra production costs for the retailer, the distributer and the manufacturer. We would have: 


$$
\left\{\begin{aligned}
& \widetilde{\Pi}_{r}= \varphi_{d r} p S_{h}(q)-\left(\widetilde{w}_{d r}+c_{r}\right) q-g_{r} L_{h}(q)+v I_{h}(q) \\
& \widetilde{\Pi}_{d}=\left(1-\varphi_{d r}\right) p S_{h}(q)+\left(\widetilde{w}_{d r}-\widetilde{w}_{m d}\right) q-c_{d} q+(b-v) I_{h}(q) \\
&-g_{d} L_{g}(q)-\gamma_{1 d}\left(q-q^{*}\right)^{+}-\gamma_{2 d}\left(q^{*}-q\right)^{+} \\
& \widetilde{\Pi}_{m}=\left(\widetilde{w}_{m d}-c_{m}\right) q-b I_{h}(q)-g_{m} L_{h}(q)-\gamma_{1 m}\left(q-q^{*}\right)^{+}-\gamma_{2 m}\left(q^{*}-q\right)^{+}
\end{aligned}\right.
$$

where $\widetilde{\Pi}_{r}, \widetilde{\Pi}_{d}, \widetilde{\Pi}_{m}$ are the expected profit of the retailer, the distributer and the manufacturer with disruption, respectively. The wholesale price with disruption will change, the wholesale price that the distributer determines for the retailer is $\widetilde{w}_{d r}$ and the wholesale price that the manufacturer determines for the distributer is $\widetilde{w}_{m d} \cdot \gamma_{1 d}>0$ is the unit extra production costs for additional products of the distributer and $\gamma_{2 d}>0$ is the unit costs the supply chain decreases the production quantity for the distributer. For the manufacturer, $\gamma_{1 m}>0$ is the unit extra production costs for additional products and $\gamma_{2 m}>0$ is the unit costs the supply chain decreases the production quantity.

The total expected profit of supply chain would be:

$\widetilde{\Pi}=\widetilde{\Pi}_{r}+\widetilde{\Pi}_{d}+\widetilde{\Pi}_{m}$

and Eq. (19) can be rewritten as below:

$\widetilde{\Pi}=p S_{h}(q)-c q-g L_{h}(q)-\left(\gamma_{1 d}+\gamma_{1 m}\right)\left(q-q^{*}\right)^{+}-\left(\gamma_{2 d}+\gamma_{2 m}\right)\left(q^{*}-q\right)^{+}$.

Disruption can be happened as two scenarios; when the market demand increases and when the market demand decreases. We will consider both cases separately and explain conditions of coordination for this kind of supply chain. Obviously, when the market demand does not change; the parameters are still valid without disruption. We let $\tilde{q}^{*}=\operatorname{argmax} \widetilde{\Pi}_{\text {for } \mathrm{q} \geq 0}$.

\subsection{When the market demand increase}

In this part, we consider the disruption as the market demand increases and define the optimal parameters for coordination of supply chain. The optimal parameters of coordinator contracts are not valid and must change.

Theorem1: If disruption makes market size increasing [which means for any $\geq 0, H(q) \leq F(q)$ ] so we will have $\tilde{q}^{*} \geq q^{*}$; and $\tilde{q}^{*}$ will calculate from the below equation:

$H(q)=\frac{p-c+g-\gamma_{1 d}-\gamma_{1 m}}{(p+g)}$.

and $\tilde{\mathrm{q}}_{1}^{*}$ is an optimal quantity calculated from above equation.

Proof: If disruption makes market size increasing, we suppose the optimal quantity is less than $q^{*}$ in this situation, then for any $q<q^{*}$ the expected profit is equal to:

$\widetilde{\Pi}=p S_{h}(q)-c q-g L_{h}(q)-\left(\gamma_{2 d}+\gamma_{2 m}\right)\left(q^{*}-q\right)^{+}$.

Since we have for any $q \geq 0, H(q) \leq F(q)$ and we know $H($.$) is strict non-decreasing function of q$, and from the assumption of $q<q^{*}$, we know $H(q) \leq H\left(q^{*}\right)$ then we will have $H\left(\widetilde{q}^{*}\right) \leq H\left(q^{*}\right) \leq$ $F\left(q^{*}\right)$, which means $\frac{p-c+g}{(p+g)}>\frac{p-c+g+\gamma_{2 d}+\gamma_{2 m}}{(p+g)}$ that it is impossible, so when disruption makes market demand increasing, the optimal production quantity of total supply chain should be more or equal to the optimal production quantity $q^{*}$. Finally, Eq. (18) will be reduced to: 
$\widetilde{\Pi}=p S_{h}(q)-c q-g L_{h}(q)-\left(\gamma_{1 d}+\gamma_{1 m}\right)\left(q-q^{*}\right)^{+}$,

while the second order condition of function $\frac{\partial^{2} \widetilde{\Pi}}{\partial q^{2}}=-(p+g) h(q)<0$ for $q>q^{*}$ is less than zero and so the expected profit function is strictly concave; Therefore, we solve $\frac{\partial \widetilde{\Pi}}{\partial q}=0$ for solving $\widetilde{\Pi}$, then we will have:

$H(q)=\frac{p-c+g-\gamma_{1 d}-\gamma_{1 m}}{(p+g)}$.

And we let $\tilde{q}_{1}^{*}$ be the optimal quantity of Eq. (24), then $q_{1}^{*}$ is a maximum point of the function $\widetilde{\Pi}$.

We need to introduce new parameters for coordination, based on Eq. (24) the optimal quantity of centralized supply chain under disruption is $\tilde{\mathrm{q}}_{1}^{*}$, so we have

$H\left(q_{1}^{*}\right)=\frac{p-c+g-\gamma_{1 d}-\gamma_{1 m}}{(p+g)}$

So for coordination, $\tilde{\mathrm{q}}_{1}^{*}$ must satisfy $\frac{\partial \Pi_{r}}{\partial \mathrm{q}}=0, \frac{\partial \Pi_{d}}{\partial \mathrm{q}}=0, \frac{\partial \Pi_{m}}{\partial \mathrm{q}}=0$, therefore, from the $\frac{\partial \Pi_{r}}{\partial \mathrm{q}}=0$, we have:

$$
\left(1-H\left(\tilde{q}_{1}^{*}\right)\right)\left(g_{r}+\varphi_{d r} p\right)+v H\left(\tilde{q}_{1}^{*}\right)-\widetilde{w}_{d r}-c_{r}
$$

Then, from the $\frac{\partial \Pi_{d}}{\partial \mathrm{q}}=0$, we have

$$
\left(1-H\left(\widetilde{q}_{1}^{*}\right)\right)\left(\left(1-\varphi_{d r}\right) p+g_{d}\right)+\widetilde{w}_{d r}-\widetilde{w}_{m d}-c_{d}+(b-v) H\left(\tilde{q}_{1}^{*}\right)-\gamma_{1 d}
$$

If two above conditions are established, $\frac{\partial \Pi_{m}}{\partial \mathrm{q}}$ would be zero and it does not have to consider that. So we can find $\widetilde{w}_{d r}$ and $\widetilde{w}_{m d}$ from Eq. (26) and Eq. (27) that we name them as $\widetilde{w}_{d r}{ }^{*}, \widetilde{w}_{m d}{ }^{*}$, respectively. If the manufacturer determines $\widetilde{w}_{m d}{ }^{*}$ and the distributer determines $\widetilde{w}_{d r}{ }^{*}$, the coordination of supply chain will be achieved while the market demand increases.

\subsection{When the market demand decreases}

In this part, we study the disruption as the market demand decreases and define the optimal parameters for coordination of supply chain.

Theorem 2: If disruption makes market size decreasing [which means for $q \geq 0, H(q) \geq F(q)$ ], so we will have $\tilde{q}^{*} \leq q^{*}$; and $\tilde{q}^{*}$ will calculate from the following equation

$H(q)=\frac{p-c+g+\gamma_{2 d}+\gamma_{2 m}}{(p+g)}$

Let $\tilde{\mathrm{q}}_{2}^{*}$ be an optimal quantity calculated from the above equation.

Proof: It is almost similar to theorem 1 then we do not have to prove it.

For establishing the coordination as the market demand decreases, based on Eq. (28) the optimal quantity of centralized supply chain is $\widetilde{\mathrm{q}}_{2}^{*}$, so we have $q_{2}^{*}$

$H\left(q_{2}^{*}\right)=\frac{p-c+g+\gamma_{2 d}+\gamma_{2 m}}{(p+g)}$

So for coordination, $q_{2}^{*}$ must satisfy $\frac{\partial \Pi_{r}}{\partial \mathrm{q}}=0, \frac{\partial \Pi_{d}}{\partial \mathrm{q}}=0, \frac{\partial \Pi_{m}}{\partial \mathrm{q}}=0$, therefore, from the $\frac{\partial \Pi_{r}}{\partial \mathrm{q}}=0$, we have: 
$\left(1-H\left(q_{2}^{*}\right)\right)\left(g_{r}+\varphi_{d r} p\right)+v H\left(q_{2}^{*}\right)-\widetilde{w}_{d r}-c_{r}=0$

Then, from the $\frac{\partial \Pi_{d}}{\partial \mathrm{q}}=0$, we have:

$\left(1-H\left(q_{2}^{*}\right)\right)\left(\left(1-\varphi_{d r}\right) p+g_{d}\right)+\widetilde{w}_{d r}-\widetilde{w}_{m d}-c_{d}+(b-v) H\left(q_{2}^{*}\right)+\gamma_{2 d}=0$

If two above conditions would be established, $\frac{\partial \Pi_{m}}{\partial q}$ would be zero and it does not have to be considered. Then we can find $\widetilde{w}_{d r}$ and $\widetilde{w}_{m d}$ from Eq. (30) and Eq. (31) that we name them $\widetilde{w}_{d r}{ }^{*}, \widetilde{w}_{m d}{ }^{*}$. If the manufacturer determines $\widetilde{w}_{m d}{ }^{*}$ and the distributer determines $\widetilde{w}_{d r}{ }^{*}$, the coordination of supply chain will be achieved when the market demand decreases.

\section{Simulation and analysis}

In this section, we present the simulations and numerical examples to describe how the model will coordinate with or without disruption. Moreover, the effect of combined contracts on supply chain will be considered and also the risk of uncertainty from disruption in model will be evaluated. We assume $c_{r}=10, c_{d}=10, c_{m}=30, g_{m}=g_{d}=g_{d}=5, v=20, \mathrm{p}=200$ and the demand is uniformely distributed, $\mathrm{D} \sim\left(\mathrm{a}_{1}, \mathrm{a}_{2}\right)$. In this part, the supply chain coordination will be evaluated by simulation in MATLAB software with and without disruption. Based on our model that has been discussed before, disruption will be considered as two separate parts.

\subsection{Supply chain without disruption}

In this part, we consider supply chain without disruption. We assume $\mathrm{a}_{1}=200, \mathrm{a}_{2}=300, \varphi_{d r}=0.5$ and $\mathrm{b}=30$ and then the optimal parameters for supply chain will calculate as: $\mathrm{q}^{*}=276.74, w_{d r}{ }^{*}=29.77$, $w_{m d}{ }^{*}=51.86, \Pi_{r}=33724, \Pi_{d}=35848, \Pi_{m}=6050, \Pi=75652$. Therefore, under the given parameters, if the manufacturer and the distributer select their wholesale prices while 51.86 and 29.77; respectively, the retailer will order the optimal quantity that coordinate the supply chain. Now, we are going to evaluate the effect of coordinator parameters on supply chain that will be shown in Table 1 and Table 2.

\subsubsection{The effect of profit sharing parameter}

Table 1 shows the optimal parameters when $b$ is constant with different amount of $\varphi_{\mathrm{dr}}$. In this situation, we want to consider the effect of profit sharing parameter on the supply chain when the parameter of the return policy contract is constant. Therefore, $w_{m d}$ and the expected profit of the manufacturer will not be changed. We have $\left(w_{d r}, \varphi_{d r}\right)$ as the parameters of the profit sharing contract. It is reasonable, when the share of the retailer $\varphi_{d r}$ increases based on the contract, the wholesale price $\left(w_{d r}\right)$ of the distributer will increase because of dependency on $\varphi_{d r}$, but this compensation will not be enough. Then, the expected profit will incerase for the retailer and the distributer will decrease. This change will not affect the expected profit of total supply chain and it will be still 75652 and the optimal order quantity will be 276.74 . This change just affect the share of profit between the retailer and the distributer.

Table 1

The effect of the profit sharing parameter

\begin{tabular}{ccccccc}
\hline$\varphi_{d r}$ & $b$ & $w_{d r}{ }^{*}$ & $w_{m d}{ }^{*}$ & $\Pi_{r}$ & $\Pi_{d}$ & $\Pi_{m}$ \\
\hline 0.4 & 30 & 25.12 & 51.86 & 26065 & 43507 & 6050 \\
0.5 & 30 & 29.77 & 51.86 & 33724 & 35848 & 6050 \\
0.6 & 30 & 34.42 & 51.86 & 41383 & 28189 & 6050 \\
0.7 & 30 & 39.07 & 51.86 & 49042 & 20530 & 6050 \\
\hline
\end{tabular}




\subsubsection{The effect of the return policy parameter}

Table 2 shows the optimal parameters when $\varphi_{\mathrm{dr}}$ is constant with different amount of $b$. In this situation, we want to consider the effect of the return policy parameter on the supply chain when the parameter of the profit sharing contract is constant. Therefore, $w_{d r}$ and the expected profit of the retailer will not be changed. We have $\left(w_{m d}, b\right)$ as the parameters of the return policy contract. When $b$ increases, $w_{m d}$ will increase and that is reasonable because of dependency on $b$. The increase of $b$ will be appropriate for the distributer, but it is not enough in comparison with the increase in $w_{m d}$. So, the expected profit for the manufacturer incerases and for the distributer decreases. This change will not affect the expected profit of total supply chain and the optimal order quantity and will be still 75652 and 276.74, respectively. This change is the exchange of the profit sharing between the manufacturer and the distributer.

Table 2

The effect of the return policy parameter

\begin{tabular}{ccccccc}
\hline$\varphi_{d r}$ & $\mathrm{~b}$ & $w_{d r}{ }^{*}$ & $w_{m d}{ }^{*}$ & $\Pi_{r}$ & $\Pi_{d}$ & $\Pi_{m}$ \\
\hline 0.5 & 25 & 29.77 & 48.02 & 33724 & 36910 & 4988 \\
0.5 & 30 & 29.77 & 51.86 & 33724 & 35848 & 6050 \\
0.5 & 35 & 29.77 & 55.70 & 33724 & 34786 & 7112 \\
0.5 & 40 & 29.77 & 59.53 & 33724 & 33724 & 8174 \\
\hline
\end{tabular}

\subsection{Supply chain under disruption}

Disruption in demand in our model has been verified as two scenarios. When the market demand increases and when the market demand decreases. In this part, we analyze the effect of disruption in two situations. We suppose $\varphi_{d r}=0.5, b=30$ as before and for this parameters, we will evaluate the effect of changes market on supply chain. For the sake of simplicity, we have supposed the distribution of the demand as same as last part, but the market demand changes.

\subsubsection{Increase in market demand}

In this part, we will investigate the effect of enhancement in market demand on supply chain and then, we assume $\gamma_{1 d}=\gamma_{1 m}=2$. Table 3 shows the increase in market demand for different size of it. The wholesale prices will increase for both the manufacturer and the distributer in comparison without disruption based on part 5.1 and it will not be adverse for the members of supply chain and also for the total supply chain. Since, the demand enhanced, the optimal order quantity, the profit of the members and the total supply chain will enhance. It is clear when compare data based on part 5.1 with data from Table 3.

Table 3

The optimal parameters with coordination when the market demand increases

\begin{tabular}{lllrrrrrrr}
\hline$\gamma_{1 d}=\gamma_{1 m}$ & $\mathrm{a}_{1}$ & $\mathrm{a}_{2}$ & $q_{1}^{*}$ & $\widetilde{w}_{d r}{ }^{*}$ & $w_{m d}{ }^{*}$ & $\widetilde{\Pi}_{r}$ & $\widetilde{\Pi}_{d}$ & $\widetilde{\Pi}_{m}$ & $\widetilde{\Pi}$ \\
\hline 2 & 210 & 320 & 292.37 & 31.35 & 53.21 & 34109 & 36852 & 6755 & 77716 \\
& 220 & 340 & 309.86 & 31.35 & 53.21 & 34976 & 37850 & 7125 & 79951 \\
& 230 & 360 & 327.35 & 31.35 & 53.21 & 35901 & 38905 & 7496 & 82302 \\
& 240 & 380 & 344.84 & 31.35 & 53.21 & 36871 & 40007 & 7867 & 84745 \\
\hline
\end{tabular}

\subsubsection{The effect of $\gamma_{1 d}, \gamma_{1 m}$ on supply chain}

Obviously, as the market demand increases, the optimal order quantity will be more than the optimal order quantity without disruption, that was shown before. So, with regard to the effect of unit extra costs for both the manufacturer and the distributer, we only need to consider supply chain under increasing demand. Table 4 shows the optimal parameters when the unit extra costs have changed. For 
evaluating this parameters, we suppose the market demand increases and after that we will keep it constant. For the simplicity, we assume $\gamma_{1 d}=\gamma_{1 m}$ and define $\mathrm{a}_{1}=220$ and $\mathrm{a}_{2}=340$. According to Table 4 , as the unit extra costs enhance, that means the risk of surplus inventory for the manufacturer and the distributer will increase and they will increase their wholesale prices to compensate a part of this risk, finally the retailer will decline the order quantity. Therefore, the expected profit of the retailer will decrease and the expected profit of the manufacturer and the distributer will increase. These are reasonable from the equations in part 4.1 and calculated data as below. The expected profit of total supply chain will also decrease, because the risk of supply chain grows up and the costs of quantity add more than the optimal quantity in situation without disruption.

Table 4

The effect of $\gamma_{1 d}, \gamma_{1 m}$ on supply chain

\begin{tabular}{crrrrrrr}
\hline$\gamma_{1 d}=\gamma_{1 m}$ & $\widetilde{w}_{d r}{ }^{*}$ & $w_{m d}{ }^{*}$ & $q_{1}^{*}$ & $\widetilde{\Pi}_{r}$ & $\widetilde{\Pi}_{d}$ & $\widetilde{\Pi}_{m}$ & $\widetilde{\Pi}$ \\
\hline 2 & 31.35 & 53.21 & 309.86 & 34976 & 37850 & 7125 & 79951 \\
3 & 32.14 & 53.88 & 308.74 & 34749 & 37863 & 7278 & 79890 \\
4 & 32.93 & 54.56 & 307.63 & 34523 & 37877 & 7431 & 79832 \\
5 & 33.72 & 55.23 & 306.51 & 3.4298 & 37892 & 7585 & 79776 \\
\hline Increase $\rightarrow$ & increase & increase & decrease & decrease & increase & increase & decrease \\
\hline
\end{tabular}

\subsubsection{Decrease in market demand}

In this part, we pursue the effect of reduction in market demand on supply chain and then, we assume $\gamma_{2 d}=\gamma_{2 m}=2$. Table 5 shows the decrease in market demand for different size of it. The wholesale prices for both the manufacturer and the distributer will decrease in comparison without disruption based on part 5.1. Based on our model and in practice, it is reasonable that the optimal order quantity, the profit of the members and the total supply chain will decline. That is obvious when we compare data based on part 5.1 with data from Table 5.

\section{Table 5}

The optimal parameters with coordination when the market demand decreases

\begin{tabular}{lllcccrrrr}
\hline$\gamma_{2 d}=\gamma_{2 m}$ & $\mathrm{a}_{1}$ & $\mathrm{a}_{2}$ & $q_{2}^{*}$ & $\widetilde{w}_{d r}{ }^{*}$ & $w_{m d}{ }^{*}$ & $\widetilde{\Pi}_{r}$ & $\widetilde{\Pi}_{d}$ & $\widetilde{\Pi}_{m}$ & $\widetilde{\Pi}$ \\
\hline 2 & 190 & 280 & 260.74 & 28.19 & 34.79 & 33393 & 38988 & 1217 & 73598 \\
& 180 & 260 & 242.88 & 28.19 & 34.79 & 32792 & 37966 & 1096 & 71854 \\
& 170 & 240 & 225.02 & 28.19 & 34.79 & 32390 & 37143 & 975 & 70508 \\
& 160 & 220 & 207.16 & 28.19 & 34.79 & 32285 & 36617 & 853 & 69755 \\
\hline
\end{tabular}

\subsubsection{The effect of $\gamma_{2 d}, \gamma_{2 m}$ on supply chain}

Once the market demand decreases, the optimal order quantity will be less than the optimal order quantity without disruption, that was shown before. Then, regarding to the effect of $\gamma_{2 d}, \gamma_{2 m}$ for both the manufacturer and the distributer respectively, we only need to consider the supply chain under decreasing demand. Table 6 shows the optimal parameters when the $\gamma_{2 d}, \gamma_{2 m}$ have changed. For evaluation of this parameters, we suppose the market demand decline one time, and after that we will keep it constant. We assume $\mathrm{a}_{1}=180$ and $\mathrm{a}_{2}=260$.

According to Table 6, when $\gamma_{2 d}$ and $\gamma_{2 m}$ increase, the risk of inventory is reduced for the manufacturer and the distributer. Then, they will decrease their wholesale prices to compensate a part of this risk so that the retailer would order more quantity to decrease their disadvantages. Consequently, the expected profit of the retailer will increase because of excess in quantity and reduction in wholesale 
price and the expected profit of the manufacturer and the distributer will decrease. These are suitable from the equations in part 4.2 and calculated data as Table 6 . The total profit of supply chain will also diminish, because the risk of supply chain increase and the costs of quantity less than the optimal quantity without any enhancement in disruption.

Table 6

The effect of $\gamma_{2 d}, \gamma_{2 m}$ on supply chain

\begin{tabular}{cccccccc}
\hline$\gamma_{2 d}=\gamma_{2 m}$ & $\widetilde{w}_{d r}{ }^{*}$ & $w_{m d}{ }^{*}$ & $q_{2}{ }^{*}$ & $\widetilde{\Pi}_{r}$ & $\widetilde{\Pi}_{d}$ & $\widetilde{\Pi}_{m}$ & $\widetilde{\Pi}$ \\
\hline 2 & 28.19 & 34.79 & 242.88 & 32792 & 37966 & 1096 & 71854 \\
3 & 27.4 & 33.93 & 243.63 & 32972 & 37955 & 858 & 71785 \\
4 & 26.6 & 33.07 & 244.37 & 33152 & 37944 & 620 & 71717 \\
5 & 25.81 & 32.21 & 245.12 & 33333 & 37935 & 383 & 71651 \\
\hline Increase $\rightarrow$ & decrease & decrease & increase & increase & decrease & decrease & decrease \\
\hline
\end{tabular}

\section{Conclusion}

This paper investigated the coordination of a three-level supply chain with one retailer, one distributer and one manufacturer that encountered with the demand disruption. One kind of product produced by the manufacturer and it is delivered to the distributer and then to the retailer before the beginning of the selling season. First, it has been shown the supply chain coordination with combined contracts consist of profit sharing contract between the retailer and the distributer and also return policy contract between the distributer and the manufacturer was achieved. Next, we displayed that the initial contracts could not attain the coordination under disruption. Therefore, with the changes in market demand, the conditions of coordination have to change. We have considered two possible scenarios for the disruption: At first, as the market demand increases and then, when the market demand decreases. In both situations, the optimal parameters for the coordination of the supply chain have been defined. We have shown, disruption can ruined the plans of coordination but with redefinition of parameters of combined contracts, the coordination can be achieved again. We have analyzed performance of our model by simulation and different examples. The effect of main parameters and increase in cost of disruption on supply chain have been presented and evaluated. When the costs of uncertainty in both scenarios increase, the total supply chain will be harmed.

\section{References}

Arshinder, Kanda, A., \& Deshmukh, S.G. (2009) .A coordination theoretic model for three level supply chains using contracts. Indian Academy of Science, 34, 767-798.

Azarmehr, M.A., Rezapour, S., \& Tavakkoli-Moghaddam, R. (2012) .Sourcing and pricing strategies for two retailers in a decentralized supply chain system under supply disruption. Management Science Letters, 2, 43-54.

Cachon, G.P. (2003) .Supply chain coordination with contracts. Handbook in OR \& MS, 11.

Cachon, G.P., \& Lariviere, M.A., (2005). Supply Chain Coordination with Revenue-Sharing Contracts: Strengths and Limitations. Management Science, 51, 30-44.

Cao, E., Wan, C., \& Lai, M., (2013) .Coordination of a supply chain with one manufacturer and multiple competing retailers under simultaneous demand and cost disruptions. International Journal of Production Research, 141, 425-433

Chen, K., \& Xiao, T. (2009) .Demand disruption and coordination of the supply chain with a dominant retailer. European Journal of Operational Research, 197, 225-234.

Chen, J. (2011). Returns with wholesale-price-discount contract in a newsvendor problem. International Journal of Production Economics, 130, 104-111.

Ding, D., \& Chen, J. (2008). Coordinating a three level supply chain with flexible return policies. Omega, 36, 865-876. 
Dana, J.D, \& Spier, K.E. (2001). Revenue sharing and vertical control in the video rental industry. Journal of Industrial Economics, 49, 223-245.

Giannoccaro, I, \& Pontrandolfo, P. (2004). Supply chain coordination by revenue sharing contract. International Journal of Production Economics, 89, 131-139.

Huang, S., Yang, C., \& Zhang, X. (2012) .Pricing and production decisions in dual-channel supply chains with demand disruptions. Computers \& Industrial Engineering, 62, 70-83.

Khedlekar, U.K. (2012). A disruption production model with exponential demand. International Journal of Industrial Engineering Computations, 3, 607-616.

Krishnan, H., \& Winter, R.A. (2011) .On the role of revenue-sharing contracts in supply chains. Operations Research Letters, 39, 28-31.

Lei, D., Li, J., \& Liu, Z. (2012). Supply chain contracts under demand and cost disruptions with asymmetric information. International Journal of Production Economics, 139, 116-126.

Mirzaee, M., Makui, A., \& Tavakoli, E.M. (2012) . Supply chain coordination under retail competition and advertising dependent demand. International Journal of Industrial Engineering Computations, 3, 383-392.

Munson, C., \& Rosenblatt, M. (2001). Coordinating a three-level supply chain with quantity discounts. IIE Transaction, 33, 371-384.

Qi, X., Bard, J.F., \& Yu, G. (2004). Supply chain coordination with demand disruptions. Omega, 32, 301-312.

Seifert, R.W., Zequeira, R.I., \& Liao, S. (2012). A three-echelon supply chain with price-only contracts and sub-supply chain coordination. International Journal of Production Economics, 138, 345-353.

Tsay, A., Nahmias, S., \& Agrawal, N. (1998). Modeling supply chain contracts: a review. in: S. Tayur, R. Ganeshan, M. Magazine (eds.), Quantitative Models for Supply Chain Management, Boston, Kluwer,

Xiao, T, Qi. X., \& Yu, G. (2007). Coordination of supply chain after demand disruptions when retailers compete. International Journal of Production Economics, 109, 162-179.

Xiao, T, \& Qi. X. (2008). Price competition, cost and demand disruptions and coordination of a supply chain with one manufacturer and two competing retailers. Omega, 36, 741-753.

Yao, Z., Leung, S.C.H., \& Lai. K.K., (2008). Analysis of the impact of price-sensitivity factors on the returns policy in coordinating supply chain. European Journal of Operational Research, 187, 275282. 